\title{
Primary graft dysfunction of the liver: definitions, diagnostic criteria and risk factors
}

\author{
Disfunção primária do enxerto hepático: definições, critérios diagnósticos e fatores de risco
}

\author{
Douglas Bastos Neves ${ }^{1,2}$, Marcela Balbo Rusi ${ }^{3}$, Luiz Gustavo Guedes Diaz ${ }^{3}$, Paolo Salvalaggio ${ }^{3}$
}

\begin{abstract}
Primary graft dysfunction is a multifactorial syndrome with great impact on liver transplantation outcomes. This review article was based on studies published between January 1980 and June 2015 and retrieved from PubMed database using the following search terms: "primary graft dysfunction", "early allograft dysfunction", "primary non-function" and "liver transplantation". Graft dysfunction describes different grades of graft ischemia-reperfusion injury and can manifest as early allograft dysfunction or primary graft non-function, its most severe form. Donor-, surgery- and recipient-related factors have been associated with this syndrome. Primary graft dysfunction definition, diagnostic criteria and risk factors differ between studies.
\end{abstract}

Keywords: Transplantation; Primary graft dysfunction/diagnosis; Liver transplantation; Donor selection; Tissue and organ procurement; Risk factors

\section{RESUMO}

A disfunção primária do enxerto hepático é uma síndrome multifatorial com grande impacto no resultado do transplante de fígado. Foi realizada uma ampla revisão da literatura, consultando a base de dados PubMed, em busca de estudos publicados entre janeiro de 1980 e junho de 2015. Os termos descritivos utilizados foram: "primary graft dysfunction", "early allograft dysfunction", "primary non-function" e "liver transplantation". A disfunção traduz graus diferentes da lesão de isquemia e reperfusão do órgão, e pode se manifestar como disfunção precoce ou, na forma mais grave, pelo não funcionamento primário do enxerto. Fatores relacionados ao doador, ao transplante e ao receptor contribuem para essa síndrome. Existem definições diferentes na literatura quanto ao diagnóstico e aos fatores de risco associados à disfunção primária.

Descritores: Transplante; Disfunção primária do enxerto/diagnóstico; Transplante de fígado; Seleção do doador; Obtenção de tecidos e órgãos; Fatores de risco

\section{INTRODUCTION}

Liver transplantation is the only choice for patients suffering from end-stage liver disease. Primary graft dysfunction (PGD), one of the major complications of liver transplantation, is associated with higher morbidity in the early post-transplant period and may compromise graft survival. ${ }^{(1-3)}$

Primary graft dysfunction is related to ischemiareperfusion injury ${ }^{(1,2)}$ to the transplanted organ and may be subdivided into early allograft dysfunction (EAD) and primary nonfunction (PNF), its more severe manifestation. ${ }^{(3,4)}$ Primary graft dysfunction occurs in $38.7 \%$ of liver transplants, ${ }^{(3)}$ with PNF incidence ranging from $0.9 \%$ to $8.5 \% .^{(1,4)}$

Several studies attempted to establish a definition of PGD and determine related diagnostic criteria and risk factors. Along with surgery-related factors, clinical and epidemiological characteristics of donors and recipients, which differ between European, North and Latin American countries, were associated with PGD. ${ }^{(1)}$

The lack of universally accepted PGD definition and diagnostic criteria and the wide variation in risk factors described in literature preclude the adoption of standardized procedures across organ transplant centers. This study set out to compile definitions, diagnostic criteria and risk factors for this significant liver transplant complication in its different manifestations (i.e., EAD and PNF).

This review was based on articles published from January 1980 to June 2015; articles were retrieved from PubMed database using the following search terms: "primary graft dysfunction", "early allograft dysfunction”,

\footnotetext{
${ }^{1}$ Hospital Federal dos Servidores do Estado, Rio de Janeiro, RJ, Brazil; Hospital São Vicente de Paulo, Rio de Janeiro, RJ, Brazil.

2 Programa de Pós-graduação em Ciências da Saúde, Hospital Israelita Albert Einstein, São Paulo, SP, Brazil.

${ }^{3}$ Hospital Israelita Albert Einstein, São Paulo, SP, Brazil.

Corresponding author: Douglas Bastos Neves - Rua Sacadura Cabral, 178, 8th floor - Saúde - Zip code: 20221-903 - Rio de Janeiro, RJ, Brazil - Phone: (55 21) 2291-3131 -E-mail: douglas.bastos@hepatobiliar.com Received on: Nov 9, 2015 - Accepted on: Apr 9, 2016

Conflict of interest: none.

DOI: 10.1590/S1679-45082016RW3585
} 
"primary non-function", and "liver transplantation". Original and review articles from Europe, United States, Canada and Asia were included. Latin American studies with sufficient statistical power were lacking. Studies involving pediatric populations, live donors, double transplants or experimental models were excluded.

\section{DEFINITION}

Early allograft dysfunction and PNF describe different degrees of graft functional impairment arising during the intraoperative period, and therefore reflect different stages of the same syndrome. However, clear definitions of EAD and PNF are lacking in medical literature.(4) While EAD refers to a set of transient clinical and laboratory changes reflecting post-transplant graft malfunction, PNF is a more severe, catastrophic event characterized by liver necrosis, rapid increase in serum transaminase, coagulopathy, increased lactate levels, hemodynamic instability, hypoglycemia and respiratory and renal failure. ${ }^{(1,5,6)}$ Different from EAD, a transient condition with potential graft function recovery, PNF leads to graft failure requiring emergency retransplantation.

\section{EARLY ALLOGRAFT DYSFUNCTION}

Variables and cut-off points employed in EAD definition and diagnosis differ between studies. Laboratory changes reflecting liver metabolism and function in the first few days after transplantation, such as serum alanine aminotransferase (ALT) and aspartate aminotransferase (AST) levels, prothrombin time (PT), international normalized ratio (INR), and serum lactate and ammonia levels, are the most commonly used parameters. ${ }^{(2,7-15)}$ Early allograft dysfunction is known to be associated with lower graft and patient survival rates, longer stay at intensive care unit (ICU) and increased postoperative morbidity and mortality. ${ }^{(9)}$

Previous studies taking time to dysfunction diagnosis as the driving factor for implementation of patient support therapy established the third postoperative day as the cut-off time for EAD. ${ }^{(10,11)}$ Nanashima et al., ${ }^{(10)}$ used serum AST or ALT levels over 1,500IU/L in two consecutive tests, within 72 hours of surgery, to define EAD. ${ }^{(11)}$ According to Dhillon et al., ${ }^{(11)}$ EAD diagnosis should be based on transaminase scores [(AST+ALT)/2] on the second postoperative day; values <285IU/L and between 285 and 986IU/L would reflect good and intermediate graft function, respectively, while values above $986 \mathrm{IU} / \mathrm{L}$ would define EAD. ${ }^{(11)}$
Graft function scores were also developed. González et al. ${ }^{(15)}$ described early graft function using a point scoring system based on serum ALT levels, bile production and prothrombin time within the first 72 hours post-transplant; laboratory test results scored 3-4, 5-6 and 7-9 would reflect good graft function, moderate graft function and EAD, respectively. ${ }^{(15)}$ Heise et al. ${ }^{(16)}$ created a survival-based classification system using serum AST and ALT levels, bile production and prothrombin time within 1, 3, 7 and 14 days of surgery. Postoperative laboratory values are known to change over time; therefore, in this system, ${ }^{(16)}$ patients initially diagnosed with EAD can be reallocated to different subgroups after the first 72 hours of surgery based on laboratory test result fluctuations. Hence, graft function is graded Berlin A (4-5 points; good graft function), Berlin B (6 points; intermediate graft function) or Berlin C (7-8 points; EAD). ${ }^{(16)}$

The widely used concept proposed by Ploeg et al.,(8) is based on hepatocyte injury and liver synthesis capacity assessment (serum transaminase levels and PT, respectively). ${ }^{(8)}$ In this unicenter study, EAD was defined as serum AST levels >2,000IU/L, PT over 16 seconds and serum ammonia levels $>50 \mu \mathrm{mol} / \mathrm{L}$ between and second and $17^{\text {th }}$ day post-surgery. ${ }^{(8)}$

In the first definition of EAD derived from a multicenter study, post-transplantation liver function, donor- and graft-related factors, and recipient pretransplantation status were described as risk factors. ${ }^{(2)}$ Serum bilirubin levels, PT and the occurrence of hepatic encephalopathy between post-transplant days 2 and 7 were taken into account. Increased PT and serum bilirubin levels prior to transplantation, recipient hospitalization due to clinical condition deterioration, donors aged 50 years or over or hospitalized for more than 3 days, and ischemic time over 15 hours were also associated with EAD. ${ }^{(2)}$

A definition of EAD based on graft function variables (injury, coagulopathy and cholestasis) up to postoperative day 7 was proposed by Olthoff and a liver transplant expert group. ${ }^{(7)}$ Rather than deriving novel variable cut-offs, the study was aimed at validation of previous definitions; objective variables that could be easily obtained over the course of patient follow-up were selected.(2,17) In that study, EAD diagnosis was established when one or more of the following variables were present: serum bilirubin levels $\geq 10 \mathrm{mg} / \mathrm{dL}$; INR $\geq 1.6$ on postoperative day 7; and serum AST or ALT levels $>2,000 \mathrm{IU} / \mathrm{L}$ within the first 7 days of surgery. ${ }^{(7)}$

Friedman et al. hypothesized that serum inflammatory protein expression in response to surgery might reflect 
EAD; ${ }^{(18)}$ hence, inflammatory cytokine profiles could be used to diagnose the condition. Multivariate analysis revealed that patients suffering from EAD had higher interleukin (IL) 6 and IL-2R levels prior to than after surgery; in contrast, MCP-1 (CCL2), IL-8 (CXCL8) and RANTES (CCL5) levels were higher immediately after than before surgery. These findings suggest potential association of several biomarkers with EAD.

Croome et al. ${ }^{(19)}$ employed MELD (Model for End-Stage Liver Disease) score derived donor data to predict EAD. The value of the MELD score in predicting EAD within the first week, or mortality within 90 days post-transplant, was emphasized by Wagener et al. ${ }^{(20)}$

A study involving 66 transplanted patients ${ }^{(21)}$ suggested peak serum AST investigation should be performed within the 5-11-hour post-reperfusion time window, given AST levels are known to drop by half within the first postoperative day. ${ }^{(21)}$ This finding is highly significant, bearing in mind the lack of a consensus among organ transplant centers as to the best time point for the first serum AST level determination. Direct liver function assessment tests, such as indocianine green clearance, can be employed for early graft dysfunction diagnosis. ${ }^{(22)}$ The application of the liver function test LiMAx (maximal liver function capacity) ${ }^{(22-24)} 24$ hours following transplant was reported by Lock et al. ${ }^{(22)}$

This test reflects real-time liver function and was shown to be successful in graft function assessment immediately after surgery. ${ }^{(22)}$ The main definitions of EAD are given on chart 1.

Chart 1. Main definitions of early allograft dysfunction

\begin{tabular}{|c|c|}
\hline Author & Definition \\
\hline Olthoff et al.!7) & $\begin{array}{l}\text { At least one of the following parameters: bilirubin } \geq 10 \mathrm{mg} / \mathrm{dL} \text { on } \\
\text { day } 7 ; \text { INR } \geq 1.6 \text { on day } 7 ; \mathrm{ALT} \text { or AST }>2,000 \mathrm{IU} / \mathrm{L} \text { up to day } 7\end{array}$ \\
\hline Ploeg et al. ${ }^{(8)}$ & $\begin{array}{c}\text { AST }>2,000 \mathrm{IU} / \mathrm{L}, \mathrm{TP}>16 \text { seconds and ammonia } \\
\quad>50 \mu \mathrm{mol} / \mathrm{L} \text { from day } 2 \text { to day } 7\end{array}$ \\
\hline Nanashima et al. ${ }^{(10)}$ & $\begin{array}{c}\text { AST or ALT }>1,500 \text { IU/L in } 2 \text { consecutive tests } \\
\text { within the first } 72 \text { hours }\end{array}$ \\
\hline Dhillon et al. ${ }^{(11)}$ & {$[($ ALT+AST)/2] $>986 I U / L$ on day 2} \\
\hline
\end{tabular}

INR: international normal ratio; ALT: alanine aminotransferase; AST: aspartate aminotransferase; TP: prothrombin time.

\section{PRIMARY NONFUNCTION}

Primary nonfunction (PNF) is the most severe manifestation of graft dysfunction..$^{(1,4)}$ Just as with EAD, a clear, universally accepted definition of PNF is lacking. However, there is one common denominator across studies: the need for early retransplantation or progression to patient death. ${ }^{(4,7-9)}$
Makowka et al. defined PNF as patient death or need for retransplantation within the first 72 hours of surgery, other causes of liver failure excluded. ${ }^{(25)}$ Ploeg et al. ${ }^{(8)}$ described PNF as liver function inconsistent with recipient survival, either progressing to patient death or requiring retransplantation within 7 days of surgery. A similar PNF definition was adopted by Broering et al., ${ }^{(12)}$, albeit with a 10-day interval from transplantation to diagnosis. On the other hand, Uemura et al. ${ }^{(1)}$ defined PNF as poor early graft condition requiring retransplantation or progressing to patient death within the first 7 days of surgery and emphasized the absence of other causes of liver failure, particularly vascular conditions, such as hepatic artery and portal vein thrombosis. ${ }^{(1,26)}$

Other authors tried to define PNF based on objective laboratory cut-off values. The following criteria were proposed by Kremers et al. ${ }^{(27)}$ serum ALT levels $>2,500 \mathrm{IU} / \mathrm{L}$, glucose levels $<60 \mathrm{mg} / \mathrm{dL}$, INR $>2.5$ or bile flow $<50 \mathrm{~mL} /$ day. Dhillon et al. ${ }^{(11)}$ associated their own EAD laboratory criteria with poor recipient progression to define PNF. ${ }^{(11)}$ PNF diagnosis would correspond to $[(\mathrm{ALT}+\mathrm{AST}) / 2]>986 \mathrm{IU} / \mathrm{L}$, on the second posttransplantation day, with need for retransplantation or progression to patient death up to day seven. Máthé et al. also based their PNF definition on laboratory criteria and clinical progression; in that study, PNF was described as all clinical cases with serum AST or ALT levels $>1,500 \mathrm{IU} / \mathrm{L}$, in two consecutive tests, within the first 72 hours post-transplantation and requiring retransplantation or progressing to recipient death. ${ }^{(28)}$

According to the strict criteria established by the United Network for Organ Sharing (UNOS; American transplantation regulatory body), PNF is defined as serum AST levels $\geq 3,000$ associated with at least one of the following: $\mathrm{NR} \geq 2.5$, acidosis corresponding to arterial $\mathrm{pH} \leq 7.30$ or venous $\mathrm{pH} \leq 7.25$ and/or serum lactate levels $\geq 4 \mathrm{mMol} / \mathrm{L}$. Researchers supporting definitions based on objective criteria argue this would simplify PNF diagnosis and promote fast reinclusion in organ transplant waiting lists, the only alternative to prevent patient death. ${ }^{(4)}$

From the clinical perspective, PNF may be defined as hyperpotassemia, increased serum lactate levels, hemodynamic instability and oliguric renal failure up to the second week post-transplant. ${ }^{(26)}$ Other clinical manifestations include persistent encephalopathy and metabolic acidosis, marked hypoglycemia, coagulopathy and reduced or absent bile production associated with progressive increase in serum AST levels. ${ }^{(29)}$ The main PNF definitions are given on chart 2. 
Chart 2. Main definitions of primary nonfunction

\begin{tabular}{|c|c|}
\hline Author & Definition \\
\hline Ploeg et al. ${ }^{(8)}$ & $\begin{array}{l}\text { Liver function inconsistent with life; need for retransplantation or } \\
\text { progression to death within seven days of surgery }\end{array}$ \\
\hline Nanashima et al. ${ }^{(10)}$ & $\begin{array}{l}\text { AST or ALT }>1,500 \mathrm{IU} / \mathrm{L} \text { in } 2 \text { consecutive tests within the first } 72 \\
\text { hours, requiring retransplantation or progressing to recipient death }\end{array}$ \\
\hline Dhillon et al.(11) & $\begin{array}{c}{[(A L T+A S T) / 2]>986 I U / L \text { on day } 2 \text {, requiring retransplantation or }} \\
\text { progressing to recipient death up to day } 7\end{array}$ \\
\hline Broering et al..$^{(12)}$ & $\begin{array}{l}\text { Need for retransplantation up to day } 10 \text { or death due } \\
\text { to graft nonfunction }\end{array}$ \\
\hline Máthé et al. ${ }^{(28)}$ & $\begin{array}{l}\text { AST or ALT }>1,500 / \mathrm{U} / \mathrm{L} \text { in } 2 \text { consecutive tests within the first } \\
72 \text { hours, leading to retransplantation or recipient death }\end{array}$ \\
\hline Kremers et al. ${ }^{(27)}$ & $\begin{array}{c}\text { ALT }>2,500 \mid \mathrm{U} / \mathrm{L}, \text { blood glucose levels }<60 \mathrm{mg} / \mathrm{dL} \text {, } \\
\text { INR }>2.5 \text { or bile flow }<50 \mathrm{~mL} / \mathrm{d}\end{array}$ \\
\hline
\end{tabular}

\section{RISK FACTORS FOR EARLY ALLOGRAFT DYSFUNCTION AND PRIMARY NONFUNCTION}

Early allograft dysfunction and PNF are multifactorial syndromes. Surgery, donor- and recipient-related factors have been described with these outcomes. ${ }^{(1,4,7,28)}$

Donor age is often emphasized in the literature; however, a clear age cut-off has not been established to date. Increased risk of EAD has been associated with liver transplantation from donors aged over $49,{ }^{(8)} 65^{(30)}$ or $45^{(7)}$ years. In the latter Olthoff et al., ${ }^{(7)}$ univariate analysis revealed a trend towards increased incidence of EAD in transplants from donors aged over 49.6 years when age (years) was treated as a continuous variable.

Hepatic steatosis is also frequently associated with EAD in the literature. Steatosis type (i.e., macro or microvesicular) or severity (mild, moderate or severe; $<30 \%, 30$ to $59 \%$, and $>60 \%$, respectively) are known to be associated with the occurrence of EAD and PNF. ${ }^{(31,32)}$ Primary nonfunction incidences of $1.8 \%$ and $5.1 \%$ were reported following transplantation of nonsteatotic grafts and grafts with macrovesicular steatosis greater than $30 \%$, respectively. ${ }^{(33)}$ In contrast, grafts with up to $30 \%$ steatosis had similar PNF indices compared to nonsteatotic grafts. ${ }^{(32)}$ Grafts with moderate steatosis (30-59\%) can be used, provided they are well allocated to recipients (i.e., recipients free from other risk factors). ${ }^{(34,35)}$ Transplantation of grafts with severe (over $60 \%$ ) steatosis is limited to a few centers; most groups choose not to use such grafts out of increased EAD and PNF risk concerns. ${ }^{(35,36)}$

Given the limited availability of grafts compared to organ demands, several transplant centers use marginal donors. Such donors are defined as expanded criteria donors according to the following: age $\geq 60$ years, body mass index $>27$ to $30 \mathrm{~kg} / \mathrm{m}^{2}$, macrovesicular steatosis $\geq 30 \%$, length of stay at ICU $>4$ to 5 days, use of vasoactive drugs (dopamine at doses $>10 \mu / \mathrm{kg} /$ minute or any other catecholamine, regardless of dosage), long- standing hypotension (over 1 hour), serum sodium levels $>150-155 \mathrm{mmol} / \mathrm{L}$, cold ischemia time $>8$ hours, hot ischemia time $>40-45$ minutes, controlled sepsis, serum creatinine levels $>1.2 \mathrm{mg} / \mathrm{dL}$, history of alcoholism, serum bilirubin, ALT and AST levels $>2.0 \mathrm{mg} / \mathrm{dL}$, $>170 \mathrm{IU} / \mathrm{L}$ and $>140 \mathrm{IU} / \mathrm{L}$, respectively. ${ }^{(37-39)}$ The use of expanded criteria donors has been largely associated with EAD. ${ }^{(37,39)}$ Donors presenting with three or more of the above described parameters are described as expanded criteria donors by most authors. ${ }^{(4,37,38)}$

The Donor Risk Index (DRI) concept was introduced by Feng et al., ${ }^{(40)}$ in 2006, to predict the risk of graft failure. The DRI corresponds to a score system based on the following donor characteristics: donor age, race and height, cause of death, donation after cardiac death, use of split/partial grafts, geographic location and cold ischemia time. While not contraindicating donor use, the DRI provides supporting data for improved graft allocation. ${ }^{(41)}$ Different from other studies addressing risk factors in a categorical manner, the index developed by Feng et al. ${ }^{(40)}$ is a quantitative graft dysfunction risk index. However, difficulties in donor racial classification and, more importantly, the use of deceased donor organs from heart-beating donors, limit DRI application in Brazil. The combined use of DRI and recipient MELD scores to predict graft survival was reported by Avolio et al. ${ }^{(42)}$

Cold and hot ischemia times were associated with EAD and PNF in several articles. (4,7,8,43) $^{-}$ However, cold ischemia time and hot ischemia time cut-offs were not clearly determined.(4) Cold ischemia times in excess of 10 hours were shown to be associated with higher incidence of EAD, PNF and biliary complications in the long term. ${ }^{(8,43)}$ Associations between prolonged hot ischemia time and greater hepatocyte damage were reported and may explain higher EAD incidences. ${ }^{(4)}$ According to Cameron et al., ${ }^{(39)}$ Hot ischemia time in excess of 40 minutes increased the risk of EAD and PNF. Hot ischemia times in excess of 45 minutes were also incriminated as independent risk factors for the same outcomes by Sirivatanauksorn et al. ${ }^{(44)}$

Recipient related factors are also known to be associated with EAD. ${ }^{(7,43,44)}$ Recipient age and race have been arguably recognized as risk factors. ${ }^{(5,39)}$ Younger recipient age has been associated with lower risks of EAD and PNF. ${ }^{(39)}$ However, given the superior overall clinical condition of younger compared to older patients, younger recipients tend to receive marginal grafts; this fact may explain the higher EAD and PNF risks documented in this age group in some studies. ${ }^{(8,43)}$ Donor, surgery and recipient related risk factors for EAD are listed on chart 3 . 
Chart 3. Major risk factors for primary graft dysfunction

\begin{tabular}{|lcc|}
\hline Donor & Surgical procedure & Recipient \\
\hline Steatosis macro $\geq 30 \% \%^{(34,36)}$ & Hot ischemia time & Young recipients (tend to \\
& $>40$ minutes $^{(39)}$ & receive organs from expanded \\
& $>45$ minutes $^{(44)}$ & criteria donors) \\
& & \\
Expanded criteria donors & \\
& Cold ischemia time & \\
Age $>49$ years $^{(1,4,43)}$ & $>10$ hours $^{(8,43)}$ & \\
$>65$ years & \\
\hline
\end{tabular}

\section{CONCLUSION}

Primary graft dysfunction can be divided into early allograft dysfunction and primary nonfunction. Early allograft dysfunction is characterized by laboratory changes within the first postoperative week and full graft recovery; in contrast, primary nonfunction is associated with clinical and laboratory catastrophic deterioration. Primary nonfunction includes primary dysfunction criteria but requires retransplantation or progresses to recipient death within the first seven days of surgery, after ruling out acute vascular complications.

Variables related to donor (age and graft steatosis) and to surgery (Cold ischemia times and Hot ischemia times) are the most commonly reported risk factors for primary graft dysfunction. The relation between recipient-related variables and graft dysfunction is less clear. The lack of a uniform, widely accepted graft dysfunction definition precludes the establishment of reproducible cut-offs across organ transplant centers.

Therefore, efforts must be directed towards the establishment of uniform early allograft dysfunction diagnostic criteria to determine the need for rapid implementation of support therapy at organ transplant centers. The use of a single test for standardized graft dysfunction diagnosis is recommended and may eliminate potential confounding factors derived from the adoption of different criteria in risk factor assessment studies. Indocyanine green clearance is thought to be one such promising tests.

\section{REFERENCES}

1. Uemura T, Randall HB, Sanchez EQ, Ikegami T, Narasimhan G, McKenna GJ, et al. Liver retransplantation for primary nonfunction: analysis of a 20-year single-center experience. Liver Transpl. 2007;13(2):227-33.

2. Deschênes M, Belle SH, Krom RA, Zetterman RK, Lake JR. Early allograft dysfunction after liver transplantation: a definition and predictors of outcome. National Institute of Diabetes and Digestive and Kidney Diseases Liver Transplantation Database. Transplantation. 1998;66(3):302-10.

3. Hoyer DP, Paul A, Gallinat A, Molmenti EP, Reinhardt R, Minor T, et al. Donor information based prediction of early allograft dysfunction and outcome in liver transplantation. Liver Int. 2015;35(1):156-63.

4. Chen XB, Xu MQ. Primary graft dysfunction after liver transplantation. Hepatobiliary Pancreat Dis Int. 2014;13(2):125-37. Review.
5. Pokorny H, Gruenberger T, Soliman T, Rockenschaub S, Längle F, Steininger R. Organ survival after primary dysfunction of liver grafts in clinical orthotopic liver transplantation. Transpl Int. 2000;13 Suppl 1:S154-7.

6. Novelli G, Rossi M, Poli L, Morabito V, Bussotti A, Pugliese F, et al. Primary nonfunction: timing retransplantation versus hemodynamic parameters and kidney function. Transplant Proc. 2008;40(6):1854-7.

7. Olthoff KM, Kulik L, Samstein B, Kaminski M, Abecassis M, Emond J, et al. Validation of a current definition of early allograft dysfunction in liver transplant recipients and analysis of risk factors. Liver Transpl. 2010;16(8):943-9.

8. Ploeg RJ, D’Alessandro AM, Knechtle SJ, Stegall MD, Pirsch JD, Hoffmann $\mathrm{RM}$, et al. Risk factors for primary dysfunction after liver transplantation--a multivariate analysis. Transplantation. 1993;55(4):807-13.

9. Deschenes M. Early allograft dysfunction: causes, recognition, and management. Liver Transpl. 2013;19 Suppl 2:S6-8.

10. Nanashima A, Pillay P, Verran DJ, Painter D, Nakasuji M, Crawford M, et al. Analysis of initial poor graft function after orthotopic liver transplantation: experience of an australian single liver transplantation center. Transplant Proc. 2002;34(4):1231-5

11. Dhillon N, Walsh L, Krüger B, Ward SC, Godbold JH, Radwan M, et al. A single nucleotide polymorphism of Toll-like receptor 4 identifies the risk of developing graft failure after liver transplantation. J Hepatol. 2010;53(1):67-72.

12. Broering DC, Topp S, Schaefer U, Fischer L, Gundlach M, Sterneck M, et al. Split liver transplantation and risk to the adult recipient: analysis using matched pairs. J Am Coll Surg. 2002;195(5):648-57.

13. Cieślak B, Lewandowski Z, Urban M, Ziarkiewicz-Wróblewska B, Krawczyk M. Microvesicular liver graft steatosis as a risk factor of initial poor function in relation to suboptimal donor parameters. Transplant Proc. 2009;41 (8):2985-8.

14. Nemes B, Gelley F, Zádori G, Piros L, Perneczky J, Kóbori L, et al. Outcome of liver transplantation based on donor graft quality and recipient status. Transplant Proc. 2010;42(6):2327-30.

15. González FX, Rimola A, Grande L, Antolin M, Garcia-Valdecasas JC, Fuster J, et al. Predictive factors of early postoperative graft function in human liver transplantation. Hepatology.1994;20(3):565-73.

16. Heise M, Settmacher U, Pfitzmann R, Wünscher U, Müller AR, Jonas S, et al. A survival-based scoring-system for initial graft function following orthotopic liver transplantation. Transpl Int. 2003;16(11):794-800.

17. Ben-Ari Z, Weiss-Schmilovitz H, Sulkes J, Brown M, Bar-Nathan N, Shaharabani $\mathrm{E}$, et al. Serum cholestasis markers as predictors of early outcome after liver transplantation. Clin Transplant. 2004;18(2):130-6.

18. Friedman BH, Wolf JH, Wang L, Putt ME, Shaked A, Christie JD, et al. Serum cytokine profiles associated with early allograft dysfunction in patients undergoing liver transplantation. Liver Transpl. 2012;18(2):166-76.

19. Croome KP, Marotta P, Wall WJ, Dale C, Levstik MA, Chandok N, et al. Should a lower quality organ go to the least sick patient? Model for end-stage liver disease score and donor risk index as predictors of early allograft dysfunction. Transplant Proc. 2012;44(5):1303-6.

20. Wagener G, Raffel B, Young AT, Minhaz M, Emond J. Predicting early allograft failure and mortality after liver transplantation: the role of the postoperative model for end-stage liver disease score. Liver Transpl. 2013;19(5):534-42.

21. Jochmans I, Monbaliu D, Pirenne J. The beginning of an end point: peak AST in liver transplantation. J Hepatol. 2014;61(5):1186-7.

22. Lock JF, Schwabauer E, Martus P, Videv N, Pratschke J, Malinowski M, et al. Early diagnosis of primary nonfunction and indication for reoperation after liver transplantation. Liver Transpl. 2010;16(2):172-80.

23. Lock JF, Malinowski M, Schwabauer E, Martus P, Pratschke J, Seehofer D, et al. Initial liver graft function is a reliable predictor of tacrolimus trough levels during the first post-transplant week. Clin Transplant. 2011;25(3):436-43.

24. Stockmann M, Lock JF, Malinowski M, Seehofer D, Puhl G, Pratschke J, et al. How to define initial poor graft function after liver transplantation? - a new functional definition by the LiMAx test. Transpl Int. 2010;23(10):1023-32.

25. Makowka L, Gordon RD, Todo S, Ohkohchi N, Marsh JW, Tzakis AG, et al. Analysis of donor criteria for the prediction of outcome in clinical liver transplantation. Transplant Proc. 1987;19(1 Pt 3):2378-82. 
26. Takaya S, Doyle H, Todo S, Irish W, Fung JJ, Starzl TE. Reduction of primary nonfunction with prostaglandin E1 after clinical liver transplantation. Transplant Proc. 1995;27(2):1862-7.

27. Kremers WK, van IJperen M, Kim WR, Freeman RB, Harper AM, Kamath PS, et al. MELD score as a predictor of pretransplant and posttransplant survival in OPTN/UNOS status 1 patients. Hepatology. 2004;39(3):764-9.

28. Máthé Z, Paul A, Molmenti EP, Vernadakis S, Klein CG, Beckebaum S, et al. Liver transplantation with donors over the expected lifespan in the model for end-staged liver disease era: is Mother Nature punishing us? Liver Int. 2011;31 (7):1054-61.

29. Monbaliu D, Libbrecht L, De Vos R, Vekemans K, Walter H, Liu Q, et al. The extent of vacuolation in non-heart-beating porcine donor liver grafts prior to transplantation predicts their viability. Liver Transpl. 2008;14(9):1256-65.

30. Corradini SG, Elisei W, De Marco R, Siciliano M, lappelli M, Pugliese F, et al. Preharvest donor hyperoxia predicts good early graft function and longer graft survival after liver transplantation. Liver Transpl. 2005;11(2):140-51.

31. Burke A, Lucey MR. Non-alcoholic fatty liver disease, non-alcoholic steatohepatitis and orthotopic liver transplantation. Am J Transplant. 2004;4(5):686-93. Review.

32. Adam R, Reynes M, Johann M, Morino M, Astarcioglu I, Kafetzis I, et al. The outcome of steatotic grafts in liver transplantation. Transplant Proc. 1991; 23(1 Pt 2):1538-40.

33. Uzun MA, Koksal N, Kadioglu H, Gunerhan Y, Aktas S, Dursun N, et al. Effects of $\mathrm{N}$-acetylcysteine on regeneration following partial hepatectomy in rats with nonalcoholic fatty liver disease. Surg Today. 2009;39(7):592-7.

34. Ureña MA, Ruiz-Delgado FC, González EM, Segurola CL, Romero CJ, García $\mathrm{IG}$, et al. Assessing risk of the use of livers with macro and microsteatosis in a liver transplant program. Transplant Proc. 1998;30(7):3288-91.
35. Hayashi M, Fujii K, Kiuchi T, Uryuhara K, Kasahara M, Takatsuki M, et al. Effects of fatty infiltration of the graft on the outcome of living-related liver transplantation. Transplant Proc. 1999;31 (1-2):403.

36. Canelo R, Braun F, Sattler B, Klinge B, Lorf T, Ramadori G, et al. Is a fatty liver dangerous for transplantation? Transplant Proc. 1999;31(1-2):414-5.

37. Briceño J, Ciria R, de la Mata M, Rufián S, López-Cillero P. Prediction of graft dysfunction based on extended criteria donors in the model for end-stage liver disease score era. Transplantation. 2010;90(5):530-9.

38. Briceño J, Solórzano G, Pera C. A proposal for scoring marginal liver grafts. Transpl Int. 2000;13 Suppl 1:S249-52.

39. Cameron AM, Ghobrial RM, Yersiz H, Farmer DG, Lipshutz GS, Gordon SA, et al. Optimal utilization of donor grafts with extended criteria: a single-center experience in over 1000 liver transplants. Ann Surg. 2006;243(6):748-53; discussion 753-5.

40. Feng S, Goodrich NP, Bragg-Gresham JL, Dykstra DM, Punch JD, DebRoy MA, et al. Characteristics associated with liver graft failure: the concept of a donor risk index. Am J Transplant. 2006;6(4):783-90.

41. Merion RM, Goodrich NP, Feng S. How can we define expanded criteria for liver donors? J Hepatol. 2006;45(4):484-8.

42. Avolio AW, Siciliano M, Barbarino R, Nure E, Annicchiarico BE, Gasbarrini A, et al. Donor risk index and organ patient index as predictors of graft survival after liver transplantation. Transplant Proc. 2008;40(6):1899-902.

43. Brokelman W, Stel AL, Ploeg RJ. Risk factors for primary dysfunction after liver transplantation in the University of Wisconsin solution era. Transplant Proc. 1999;31(5):2087-90.

44. Sirivatanauksorn $Y$, Taweerutchana $V$, Limsrichamrern $S$, Kositamongkol $P$, Mahawithitwong $P$, Asavakarn $S$, et al. Recipient and perioperative risk factors associated with liver transplant graft outcomes. Transplant Proc. 2012; 44(2):505-8. 